\title{
The effect of distance on observed mortality, childhood pneumonia and vaccine efficacy in rural Gambia
}

\author{
S. M.A. ZAMAN ${ }^{1}$, J. COX ${ }^{2}$, G. C. ENWERE ${ }^{1}$, C. BOTTOMLEY ${ }^{3}$, \\ B. M. GREENWOOD ${ }^{2}$ AND F. T. CUTTS ${ }^{1}$ \\ ${ }^{1}$ Medical Research Council Unit, Banjul, The Gambia \\ ${ }^{2}$ Department of Disease Control, London School of Hygiene \& Tropical Medicine, London, UK \\ ${ }^{3}$ Medical Research Council Tropical Epidemiology Group, Department of Infectious Disease Epidemiology, \\ London School of Hygiene \& Tropical Medicine, London, UK
}

Received 19 September 2013; Final revision 29 November 2013; Accepted 29 January 2014

\section{SUMMARY}

We investigated whether straight-line distance from residential compounds to healthcare facilities influenced mortality, the incidence of pneumonia and vaccine efficacy against pneumonia in rural Gambia. Clinical surveillance for pneumonia was conducted on 6938 children living in the catchment areas of the two largest healthcare facilities. Deaths were monitored by three-monthly home visits. Children living $>5 \mathrm{~km}$ from the two largest healthcare facilities had a $2.78[95 \%$ confidence interval (CI) 1.74-4.43] times higher risk of all-cause mortality compared to children living within $2 \mathrm{~km}$ of these facilities. The observed rate of clinical and radiological pneumonia was lower in children living $>5 \mathrm{~km}$ from these facilities compared to those living within $2 \mathrm{~km}$ [rate ratios $0.65(95 \%$ CI $0.57-0.73)$ and 0.74 (95\% CI 0.55-0.98), respectively]. There was no association between distance and estimated pneumococcal vaccine efficacy. Geographical access to healthcare services is an important determinant of survival and pneumonia in children in rural Gambia.

Key words: Access to healthcare facilities, all-cause mortality, distance, pneumococcal conjugate vaccine, pneumonia, vaccine efficacy.

\section{INTRODUCTION}

Studies in sub-Saharan Africa have shown that distance to a healthcare facility is an important determinant of mortality in children aged $<5$ years [1-6] and also a determinant of hospital attendance for fever [7], diarrhoea [8], or hospital admission with an acute lower respiratory tract infection (ALRI) for children [9]. Only a few studies have taken account of seasonal

\footnotetext{
* Author for correspondence: Dr S. M. A. Zaman, Child Survival Theme, Medical Research Council Unit, Atlantic Road, Fajara, P.O. Box 273 Banjul, The Gambia.

(Email: azaman@mrc.gm)
}

differences while evaluating access to healthcare facilities $[3,6,7,10]$ or the quality of care that they provide. None of the studies have evaluated the influence of distance to a healthcare facility on observed incidence of WHO-defined clinical pneumonia [11] or radiological pneumonia [12], and vaccine efficacy (VE) against radiological pneumonia.

Radiological pneumonia is an important endpoint of trials of vaccines against respiratory infections [13-15]. The chance of detecting radiological changes in a child with pneumonia may be influenced by the stage of the illness at presentation, and hence by the ease of access to a healthcare facility. Children who live near a healthcare facility may, on average, seek 


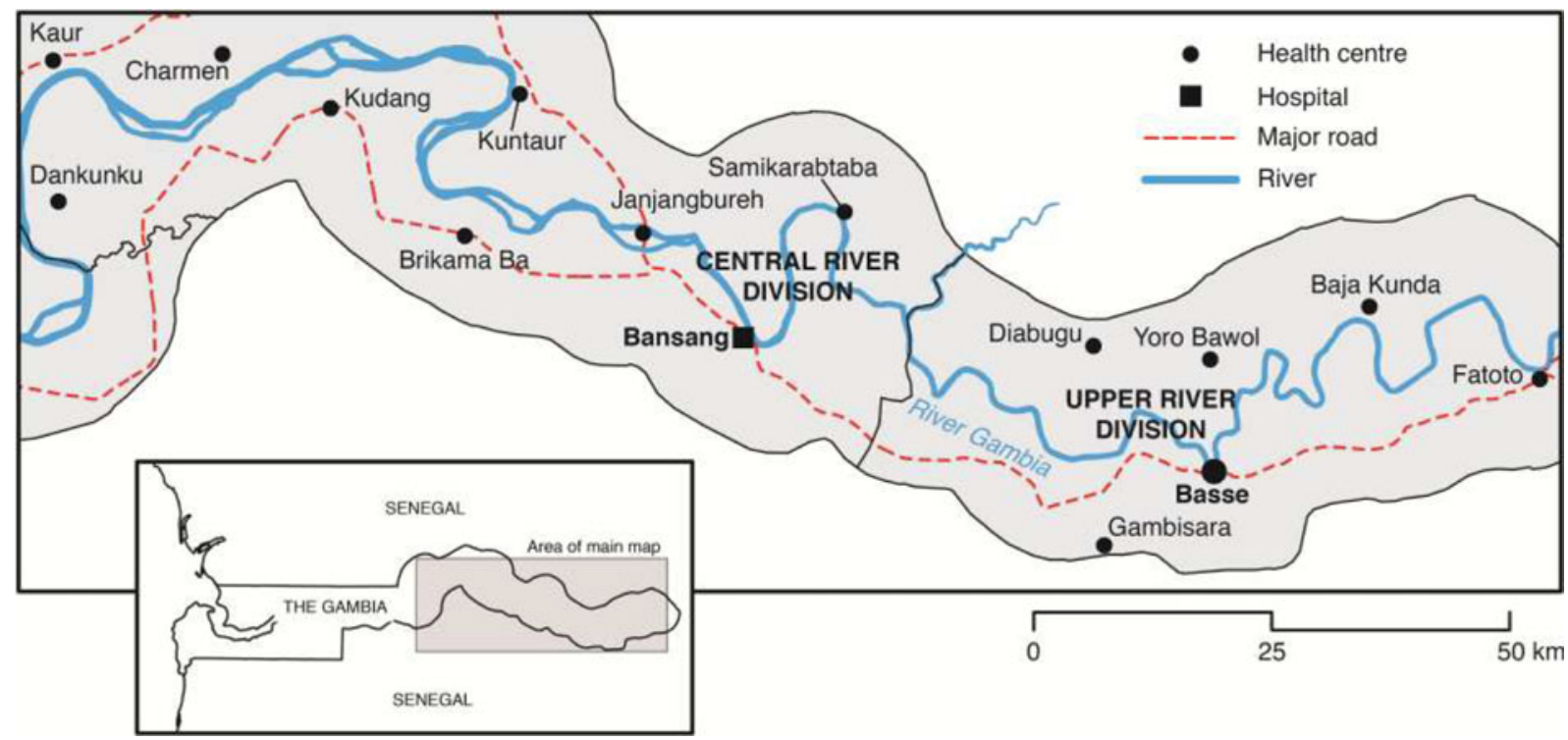

Fig. 1 [colour online]. Map showing fixed healthcare facilities in Upper and Central River Divisions of the The Gambia which participated in the surveillance of pneumonia in the Gambia Pneumococcal Vaccine Trial.

care for pneumonia at a relatively early stage, before the development of consolidation, while those living further away are more likely to report when consolidation has developed. If a vaccine is efficacious, its effectiveness in reducing radiological pneumonia will be more apparent in this group. Understanding the relationship between geographical access to healthcare facilities and the clinical characteristics of invasive pneumococcal disease and pneumonia is important.

The differences in perceived risk and corresponding gain from visiting different tiers of healthcare services with different levels of function, staffing, and provision of clinical care may result in differential utilization of healthcare services and outcome for different diseases. The impact of distance to different tiers of healthcare facilities on observed mortality, incidence of clinical and radiological pneumonia, and VE against radiological pneumonia in children has not been studied in a comprehensive population-based prospective cohort study.

In most of sub-Saharan Africa it is difficult to conduct a cohort study because of absence of reliable information on births and deaths and also because of poor public health infrastructure. The pneumococcal vaccine trial conducted in a rural area of The Gambia from 2000 to 2004 [13] provided a unique opportunity to conduct this cohort study because of the establishment of a system of registration of births and of surveillance systems for pneumonia and mortality.
We investigated the following hypotheses in this cohort study.

- Mortality rates increase with increasing distance from the nearest healthcare facility.

- Observed incidence rates of clinical and radiological pneumonia fall with increasing distance from the nearest healthcare facility.

- Observed VE against radiological pneumonia increases with increasing distance from the nearest healthcare facility.

\section{METHODS}

\section{Study area}

The 9-valent pneumococcal conjugate vaccine trial (PVT) study area included almost all of the Upper River Division (URD) and Central River Division (CRD) of The Gambia, an area of about $500 \mathrm{~km}^{2}$ (Fig. 1). The climate is highly seasonal with a wet season between July and November and a dry season between December and June. A tarmac road runs almost parallel to the south bank of the river and connects the main healthcare facilities on the south bank. A network of dirt roads connects the rest of the area; some of these become impassable in the rainy season. Most people walk to the nearest clinic. The main modes of transport for people living further away are bush taxi, donkey carts and, occasionally, scooters 
or bicycles. Most families live in mud-walled and thatched-roof houses. Subsistence farming is the main socioeconomic activity.

During the period of the trial, care for sick children was available free of charge from Government-run mother-and-child health $(\mathrm{MCH})$ services, provided through 15 fixed facilities (at least once per week) and about 110 additional outreach clinics (up to four visits per month) (Fig. 1). The larger facilities, run by doctors, nurses and other auxiliary staff, provide outpatient and limited in-patient services, while the smaller ones have no resident doctor and provide only outpatient services. A village health worker (VHW) and traditional birth attendant provide primary care in rural settlements with a population of $\geqslant 400$ persons. VHWs have been trained to recognize and treat ALRI in children. Access to antibiotics from private practitioners or pharmacies is very limited. During the trial, PVT staff based at the two largest healthcare facilities in the area, Bansang Hospital (BN) in CRD and Basse Health Centre (BS) in URD, provided 24-h paediatric care with oxygen, broad spectrum antibiotics, radiographs, laboratory investigations including blood cultures and microscopy for malarial parasites, and blood transfusion. There was no fee for consultation at $\mathrm{MCH}$ clinics or BN/BS. There was no system of health insurance in place.

\section{The PVT}

The methods used in the PVT have been described previously and are summarized briefly below [13]. This was an individually randomized, double-blind, placebo-controlled trial undertaken in URD and CRD. Infants who presented to a Government vaccination post and were resident in the trial area were eligible for enrolment in the trial. Infants who intended to move out within 4 months, had already received a dose of diphtheria-pertussis-tetanus-Haemophilus influenzae type b (DPT-Hib) or DPT vaccine, were aged $<40$ days or $>364$ days, had participated in a previous vaccine trial or had a serious chronic illness were not eligible. During the trial 17437 children were randomized to receive three doses of 9-valent pneumococcal conjugate vaccine $(\mathrm{PCV})$ given with DTP-Hib vaccine or DTP-Hib vaccine with placebo. Enrolment began in August 2000 with active surveillance of mortality and enhanced passive surveillance for pneumonia. All children enrolled in the trial were followed-up until they were aged 30 months or up to 30 April 2004, or until death or withdrawal from the trial, whichever was earlier. The median duration of follow up was 87 weeks.

\section{Detection of cases of pneumonia and deaths}

'Radiological pneumonia' (primary endpoint pneumonia), as defined by the WHO [12], was the primary endpoint of the PVT; 'clinical pneumonia', defined according to the WHO criteria for ALRI [11], was a secondary endpoint and all-cause mortality was an additional endpoint.

Health-facility-based surveillance was conducted at $\mathrm{BN}$ and $\mathrm{BS}$ for clinical pneumonia and invasive pneumococcal disease (IPD). Outreach sites of BS were visited regularly by study personnel from the beginning of the PVT and, from April 2003, outreach sites of $\mathrm{BN}$ and seven additional healthcare centres were visited regularly. Children suspected of having pneumonia or IPD were referred to BN/BS for investigation by study nurses and doctors using standard operating procedures, including a chest radiograph for children with clinical pneumonia (radiographs were not available elsewhere). Deaths were monitored by 3-monthly home visits and at BN/BS. The sensitivity of mortality surveillance was therefore high and equal across the study area while the sensitivity of pneumonia surveillance varied according to the chance of the child attending BN or BS, which was expected to vary by distance.

\section{Mapping}

Hand-held global positioning systems (GeoExplorer III, Trimble Navigation, USA) were used to record the longitude and latitude of residential compounds in the catchment areas of BN/BS and areas between them on the south of the river. Straight-line (Euclidian) distances from a compound to both the nearest outreach clinic and to the nearer of BN/BS were calculated using ArcGIS 9.2 software (ESRI, USA). In addition, an isotropic time surface approach was used to incorporate effects of existing transport routes and barriers to movement on travel time [16]. We assessed the use of theoretical travel time as an alternative indicator of access, but straight-line distances and modelled travel times in the study area were highly correlated (Pearson's correlation coefficient, $r=0 \cdot 79$ ). Since travel time can vary greatly by season, availability of transport, physical fitness of the carer, etc., we present results based on straight-line distance. 
Table 1. Baseline characteristics of all study children $(N=6938)$

\begin{tabular}{|c|c|c|c|c|}
\hline \multirow[b]{2}{*}{ Characteristics } & \multicolumn{2}{|c|}{ Straight line distance to BN/BS } & \multicolumn{2}{|c|}{ Straight line distance to $\mathrm{MCH}$ clinic } \\
\hline & $\leqslant 5 \mathrm{~km}$ & $>5 \mathrm{~km}$ & $\leqslant 5 \mathrm{~km}$ & $>5 \mathrm{~km}$ \\
\hline \multicolumn{5}{|c|}{ Age at enrolment } \\
\hline$\leqslant 6$ months & $1426(96)$ & $5065(93)$ & $6313(94)$ & $178(94)$ \\
\hline$>6$ months & $59(4)$ & $388(7)$ & $435(6)$ & $12(6)$ \\
\hline \multicolumn{5}{|l|}{ Gender } \\
\hline Male & $750(51)$ & $2800(51)$ & $3448(51)$ & $102(54)$ \\
\hline Female & $735(49)$ & 2653 (49) & $3300(49)$ & $88(46)$ \\
\hline \multicolumn{5}{|l|}{ Ethnicity } \\
\hline Mandinka & $736(50)$ & $1316(24)$ & $2036(30)$ & $16(8)$ \\
\hline Fula & $400(27)$ & $1903(35)$ & $2169(32)$ & $134(71)$ \\
\hline Serahule & $213(14)$ & $1840(34)$ & $2019(30)$ & $34(18)$ \\
\hline Wollof & $81(5)$ & $324(6)$ & $399(6)$ & $6(3)$ \\
\hline Other & $55(4)$ & $66(1)$ & $121(2)$ & 0 \\
\hline Not known & 0 & $4(0 \cdot 1)$ & $4(0 \cdot 1)$ & 0 \\
\hline \multicolumn{5}{|l|}{ Received PCV } \\
\hline No & $731(49)$ & $2736(50)$ & $3382(50)$ & $85(45)$ \\
\hline Yes & $754(51)$ & $2717(50)$ & $3366(50)$ & $105(55)$ \\
\hline
\end{tabular}

BN, Bansang Hospital; BS, Basse Health Centre; MCH, Mother and Child Health; PCV, pneumococcal conjugate vaccine. Values given are $n(\%)$.

A number of studies have used $5 \mathrm{~km}$ as the cut-off for assessing the association between distance to a healthcare facility and the risk of mortality [2, 4-6]. Therefore, we categorized straight-line distance as $<2,2-5$ and $>5 \mathrm{~km}$ in order to estimate risk for mortality and pneumonia.

\section{Statistical analysis}

The main endpoints for this analysis were rates of allcause mortality, clinical and radiological pneumonia and VE against radiological pneumonia. A piecewise exponential survival model was used to estimate the effect of distance on time to first episode of each endpoint and to test whether observed VE ( 1 - rate ratio) against radiological pneumonia was modified by geographical accessibility to radiographs at BN/BS. We assumed that the hazard was approximately constant in each age-calendar time band. By choosing this model we did not have to choose a functional form for the hazard. We compared the results of the piecewise exponential model to those of the Cox proportional hazard model, and found that the results were very similar for both models. We present the results of the piecewise exponential model since it is conceptually simpler. We accounted for clustering in compounds by using robust estimates of standard errors. A Wald test was used to test for an interaction between child age and distance to healthcare facility (i.e. the proportional hazards assumption).

Children contributed to follow-up time from the date of first vaccination until the outcome of interest, end of PVT or date of withdrawal. Follow-up was partitioned by age, period of surveillance and season. In the regression models, we included PCV vaccination status, gender, and ethnicity as baseline characteristics, and periods of surveillance, season and age groups as time-varying covariates. A Kaplan-Meier analysis was used to estimate the cumulative incidence of mortality and pneumonia as a function of followup time. For simplicity we neglected death as a competing risk for pneumonia. However, since deaths are relatively rare, the estimate is a good approximation of pneumonia risk. We used Stata v. 12.0 for Windows (StataCorp LP, USA) for our analyses.

\section{RESULTS}

\section{Characteristics of the study children}

In the PVT, 8489 children were enrolled in the catchment areas of $\mathrm{BN}$ and $\mathrm{BS}$ and in the area between them; $6938(82 \%)$ children had data on residential compound coordinates and were included in this analysis (Table 1). The children lived in 3136 compounds. The average distance between a residential 
compound and the nearer of BN/BS was $11.2 \mathrm{~km}$ (s.D. $=6 \cdot 7$, range $0 \cdot 1-27 \cdot 1$ ).

Most $(79 \%)$ children lived $>5 \mathrm{~km}$ from $\mathrm{BN} / \mathrm{BS}$, whereas only $3 \%$ lived $>5 \mathrm{~km}$ from the nearest MCH clinic (including outreach clinics) (Table 1). Distance from BN/BS was greater for children aged $>6$ months at enrolment, and varied by ethnic group but not by gender. The distance to a $\mathrm{MCH}$ clinic did not vary by age or gender but a significantly higher proportion of Fula lived $>5 \mathrm{~km}$ from a $\mathrm{MCH}$ clinic compared to other ethnic groups $(P<0 \cdot 001)$.

\section{Number of deaths and first episodes of clinical and radiological pneumonia}

There were 370 deaths; $176(47 \cdot 6 \%)$ occurred in PCV-vaccinated children and 175 (47.3\%) occurred in male children (Table 2). The median age at death was 14 months (interquartile range 9-20 months). Two hundred and twenty-nine (62\%) deaths occurred in the rainy season. There were 3264 first episodes of clinical pneumonia and 542 of radiological pneumonia, $1934(59 \cdot 3 \%)$ and $241(44 \cdot 5 \%)$ of which were reported in the rainy season.

\section{Influence of distance to BN/BS or a MCH clinic on mortality}

\section{Distance to BN/BS}

Mortality in control children increased with distance from BN/BS up to $11-15 \mathrm{~km}$ then fell to the rate observed at $6-10 \mathrm{~km}$ (Fig. $2 a$ ). The estimated probabilities of death during $\sim 2$ years of follow-up in control children living $\leqslant 5 \mathrm{~km}$ vs. $>5 \mathrm{~km}$ from $\mathrm{BN} / \mathrm{BS}$ were $3.8[95 \%$ confidence interval (CI) 2.7-5.5] and $6 \cdot 5 \%(95 \%$ CI $5 \cdot 5-7 \cdot 5)$, respectively (Fig. $3 a$ ). Similar, significant differences were found in PCVvaccinated children (data not shown).

Mortality in all study children (PCV-vaccinated and control), was significantly higher in children living $>5 \mathrm{~km}$ from BN/BS than in those living nearer to BN/BS (Table 2). The mortality rate in children living $>5 \mathrm{~km}$ from BN/BS was 2.78 (95\% CI $1.74-4.43)$ times higher than in those living within $2 \mathrm{~km}$ (Table 3 ).

\section{Distance to MCH clinics}

Mortality was not associated with distance to the nearest MCH clinic (Tables 2 and 3).
Influence of distance to BN/BS or a $\mathrm{MCH}$ clinic on observed rates of clinical and radiological pneumonia Distance to BN/BS

Rates of both clinical and radiological pneumonia in control children increased up to a distance of $2 \mathrm{~km}$ then decreased with increasing distance to BN/BS, but the rates flattened off after about $5 \mathrm{~km}$ (Fig. $2 b$, $c$ ). The estimated probabilities of detection of clinical pneumonia in control children living $\leqslant 5 \mathrm{~km} v s$. $>5 \mathrm{~km}$ of BN/BS during 2 years of follow-up were $62 \%(95 \%$ CI $58-65)$ and $46 \%$ (95\% CI $44-49)$, respectively (Fig. $3 b$ ). Corresponding figures for radiological pneumonia were $14 \cdot 5 \%(95 \%$ CI $12 \cdot 1-17 \cdot 4)$ and $8 \cdot 5 \%(95 \%$ CI $7 \cdot 5-9 \cdot 7)$, respectively (Fig. 3c). Similar significant differences were found in PCVvaccinated children (data not shown).

The observed rate of clinical pneumonia was 35\% (95\% CI 27-43) lower and that of radiological pneumonia $26 \%$ (95\% CI 2-45) lower in all children living $>5 \mathrm{~km}$ from BS/BN compared to children living within $2 \mathrm{~km}$ (Table 3 ).

\section{Distance to $\mathrm{MCH}$ clinics}

For all study children, the observed rate of clinical pneumonia increased with increase in distance to MCH clinics (Table 2). Compared to children living $<2 \mathrm{~km}$ from the nearest $\mathrm{MCH}$ clinic, those living $2-5 \mathrm{~km}$ and $>5 \mathrm{~km}$ from the nearest $\mathrm{MCH}$ clinic were $1.24(95 \%$ CI $1 \cdot 135-1 \cdot 354)$ and 1.49 (95\% CI $1 \cdot 21-1 \cdot 83)$ times, respectively, more likely to be diagnosed with clinical pneumonia (Table 3). Observed rates of radiological pneumonia were not statistically significantly associated with distance to the nearest MCH clinic (Tables 2 and 3).

\section{Influence of distance to BN/BS on observed pneumococcal VE}

Observed VE against radiological pneumonia was similar $(33 \%, 95 \%$ CI $20-44)$ for children included in the current analysis to that reported previously in the entire study population $(n=17437)$ [13] and was not confounded by distance to BN/BS or to the nearest MCH clinic (Table 3). Observed VE was also not modified by distance to BN/BS or to the nearest $\mathrm{MCH}$ clinic (data not shown).

There was no evidence for an interaction between age and distance to the healthcare facility. 
Table 2. Rates per 1000 child-years and 95\% confidence intervals of all-cause mortality, clinical pneumonia and radiological pneumonia in all study children by risk groups

\begin{tabular}{|c|c|c|c|c|c|c|c|c|c|}
\hline \multirow[b]{2}{*}{ Variables } & \multicolumn{3}{|c|}{ All-cause mortality } & \multicolumn{3}{|c|}{ Clinical pneumonia } & \multicolumn{3}{|c|}{ Radiological pneumonia } \\
\hline & $\begin{array}{l}\text { No. of } \\
\text { events }\end{array}$ & $\begin{array}{l}\text { CY } \\
\text { (in 1000s) }\end{array}$ & $\begin{array}{l}\text { Rate/1000 CY } \\
(95 \% \mathrm{CI})\end{array}$ & $\begin{array}{l}\text { No. of } \\
\text { events }\end{array}$ & $\begin{array}{l}\text { CY } \\
\text { (in 1000s) }\end{array}$ & $\begin{array}{l}\text { Rate } / 1000 \mathrm{CY} \\
(95 \% \mathrm{CI})\end{array}$ & $\begin{array}{l}\text { No. of } \\
\text { events }\end{array}$ & $\begin{array}{l}\text { CY } \\
\text { (in 1000s) }\end{array}$ & $\begin{array}{l}\text { Rate/1000 CY } \\
(95 \% \mathrm{CI})\end{array}$ \\
\hline \multicolumn{10}{|l|}{ Pneumococcal conjugate vaccine } \\
\hline Placebo & 194 & $6 \cdot 3$ & $30(26-34)$ & 1649 & $4 \cdot 6$ & $355(339-373)$ & 320 & $6 \cdot 4$ & $50(45-56)$ \\
\hline Vaccine & 176 & $6 \cdot 5$ & $27(23-31)$ & 1615 & $4 \cdot 7$ & $342(326-359)$ & 222 & $6 \cdot 5$ & $34(30-39)$ \\
\hline \multicolumn{10}{|l|}{ Distance to nearer of BN/BS $(\mathrm{km})$} \\
\hline$<2$ & 19 & $1 \cdot 4$ & $14(9-21)$ & 427 & $0 \cdot 9$ & $491(446-540)$ & 67 & $1 \cdot 4$ & $49(39-63)$ \\
\hline $2-5$ & 27 & $1 \cdot 4$ & $19(13-28)$ & 456 & $0 \cdot 9$ & $524(478-574)$ & 99 & $1 \cdot 3$ & $74(61-90)$ \\
\hline$>5$ & 324 & $10 \cdot 3$ & $32(28-35)$ & 2381 & $7 \cdot 6$ & $313(300-325)$ & 376 & $10 \cdot 2$ & $37(33-41)$ \\
\hline \multicolumn{10}{|c|}{ Distance to nearest local $\mathrm{MCH}$ clinic $(\mathrm{km})$} \\
\hline$<2$ & 244 & $8 \cdot 4$ & $29(26-33)$ & 1939 & $6 \cdot 2$ & $315(301-329)$ & 317 & $8 \cdot 3$ & $38(34-43)$ \\
\hline $2-5$ & 117 & $4 \cdot 3$ & $27(23-33)$ & 1223 & $3 \cdot 0$ & $414(391-438)$ & 210 & $4 \cdot 2$ & $50(43-57)$ \\
\hline$>5$ & 9 & $0 \cdot 4$ & $26(13-49)$ & 102 & $0 \cdot 2$ & $424(349-514)$ & 15 & $0 \cdot 3$ & $43(26-72)$ \\
\hline \multicolumn{10}{|l|}{ Season } \\
\hline Dry & 141 & $7 \cdot 9$ & $18(15-21)$ & 1330 & $5 \cdot 6$ & $238(225-251)$ & 301 & $7 \cdot 7$ & $39(35-44)$ \\
\hline Rainy & 229 & $5 \cdot 2$ & $44(39-50)$ & 1934 & $3 \cdot 7$ & $515(492-538)$ & 241 & $5 \cdot 1$ & $47(41-53)$ \\
\hline \multicolumn{10}{|l|}{ Surveillance period } \\
\hline 1 Aug. 2000 to 31 Jan. 2002 & 82 & $2 \cdot 4$ & $34(27-42)$ & 646 & $2 \cdot 0$ & $316(293-342)$ & 55 & $2 \cdot 4$ & $23(17-29)$ \\
\hline 1 Feb. 2002 to 31 Mar. 2003 & 164 & $5 \cdot 6$ & $29(25-34)$ & 1318 & $4 \cdot 3$ & $303(288-320)$ & 208 & $5 \cdot 6$ & $37(32-43)$ \\
\hline 1 Apr. 2003 to 30 Apr. 2004 & 124 & $5 \cdot 0$ & $25(21-29)$ & 1300 & $3 \cdot 0$ & $437(414-462)$ & 279 & $4 \cdot 9$ & $57(51-65)$ \\
\hline \multicolumn{10}{|c|}{ Age groups during follow-up (months) } \\
\hline$<12$ & 151 & $5 \cdot 2$ & $29(25-34)$ & 1689 & $4 \cdot 4$ & $380(362-398)$ & 250 & $5 \cdot 1$ & $49(43-55)$ \\
\hline$\geqslant 12$ & 219 & $7 \cdot 9$ & $28(24-32)$ & 1575 & $4 \cdot 9$ & $320(305-337)$ & 292 & $7 \cdot 8$ & $38(34-42)$ \\
\hline \multicolumn{10}{|l|}{ Gender } \\
\hline Male & 175 & $6 \cdot 7$ & $26(22-30)$ & 1732 & $4 \cdot 7$ & $368(351-385)$ & 300 & $6 \cdot 6$ & $46(41-51)$ \\
\hline Female & 195 & $6 \cdot 4$ & $31(27-35)$ & 1532 & $4 \cdot 6$ & $330(314-347)$ & 242 & $6 \cdot 3$ & $38(34-43)$ \\
\hline \multicolumn{10}{|l|}{ Ethnic group } \\
\hline Mandinka & 115 & $3 \cdot 9$ & $29(24-35)$ & 1104 & $2 \cdot 6$ & $421(397-446)$ & 173 & $3 \cdot 9$ & $45(39-52)$ \\
\hline Fula & 137 & $4 \cdot 2$ & $32(27-38)$ & 1038 & $3 \cdot 1$ & $335(315-356)$ & 167 & $4 \cdot 2$ & $39(34-46)$ \\
\hline Serahule & 98 & $3 \cdot 9$ & $25(20-30)$ & 776 & $3 \cdot 1$ & $254(237-273)$ & 141 & $3 \cdot 9$ & $36(31-43)$ \\
\hline Wollof & 11 & $0 \cdot 7$ & $15(8-28)$ & 283 & $0 \cdot 4$ & $661(588-743)$ & 53 & $0 \cdot 7$ & $78(59-102)$ \\
\hline Other & 8 & $0 \cdot 2$ & $35(18-70)$ & 62 & $0 \cdot 2$ & $409(319-524)$ & 7 & $0 \cdot 2$ & $31(15-65)$ \\
\hline Total & 370 & $13 \cdot 1$ & $28(26-31)$ & 3264 & $9 \cdot 3$ & $349(337-361)$ & 542 & $12 \cdot 9$ & $42(39-46)$ \\
\hline
\end{tabular}

CY, Child-years; CI, confidence interval; BN, Bansang Hospital; BS, Basse Health Centre; MCH, Mother and Child Health. 


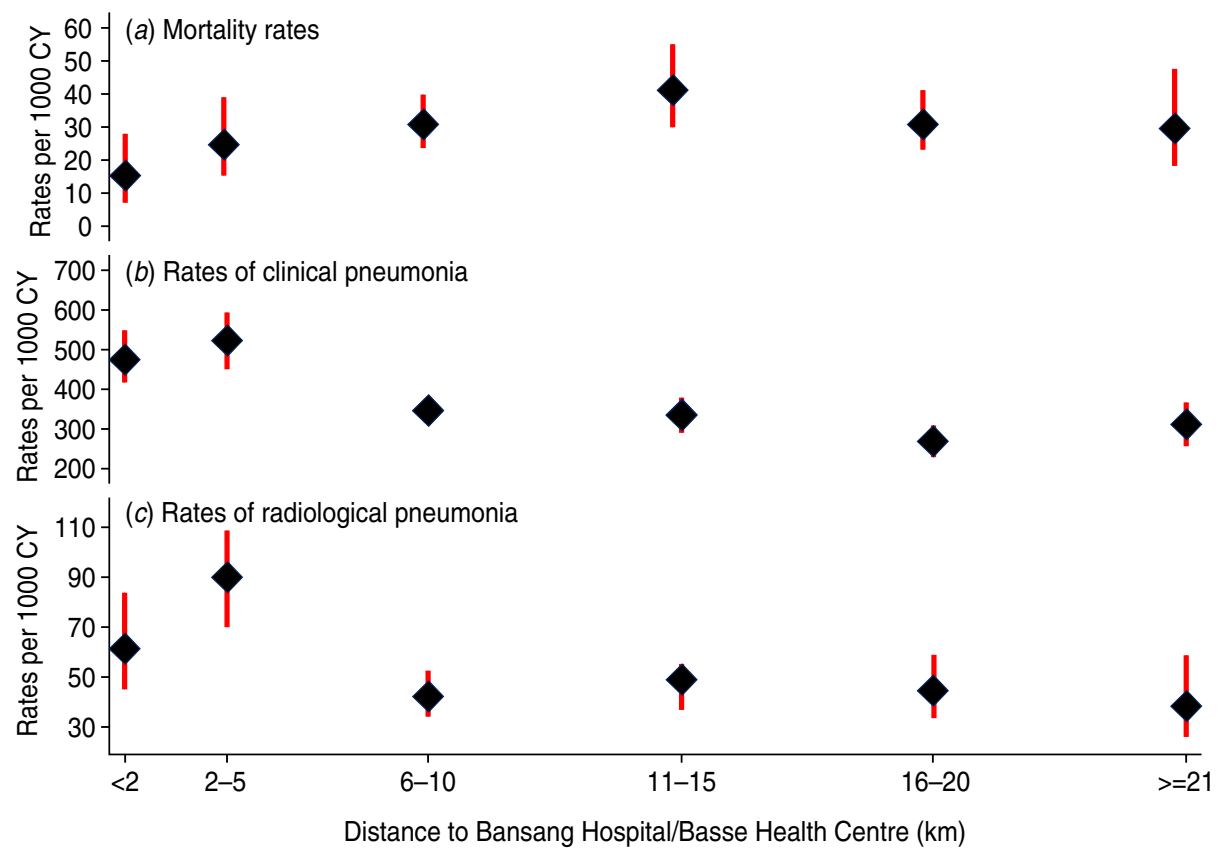

Fig. 2 [colour online]. Mortality rates, observed rates of clinical and radiological pneumonia with $95 \%$ confidence intervals in control (unvaccinated) children by distance fom their residential compounds to the nearer of Bansang Hospital or Basse Health Centre.

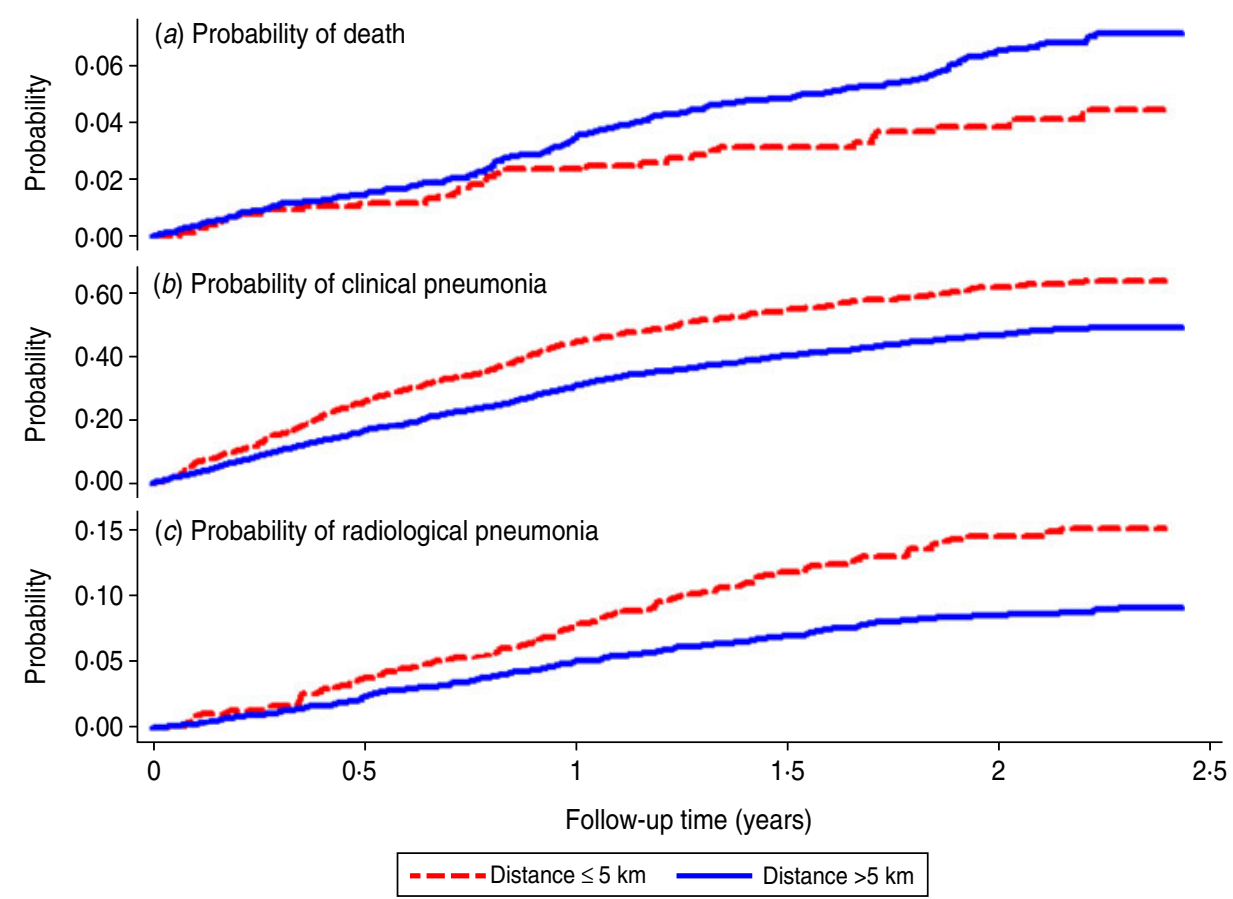

Fig. 3 [colour online]. Kaplan-Meier survival curve showing the probability of death, clinical pneumonia and radiological pneumonia in control (unvaccinated) children by follow-up time and distance from their residential compounds to the nearer of Bansang Hospital or Basse Health Centre. 
Table 3. Risk factors for all-cause mortality and observed pneumonia (number of children included in the analysis $=$ 6938)

\begin{tabular}{|c|c|c|c|}
\hline Variables & $\begin{array}{l}\text { Model } 1 \\
\text { Mortality } \\
\operatorname{RR}(95 \% \mathrm{CI}) \dagger\end{array}$ & $\begin{array}{l}\text { Model } 2 \\
\text { Clinical pneumonia } \\
\operatorname{RR}(95 \% \mathrm{CI}) \dagger\end{array}$ & $\begin{array}{l}\text { Model } 3 \\
\text { Radiological pneumonia } \\
\operatorname{RR}(95 \% \mathrm{CI}) \dagger\end{array}$ \\
\hline \multicolumn{4}{|l|}{ Pneumococcal conjugate vaccine } \\
\hline Placebo & Ref. & Ref. & Ref. \\
\hline Vaccine & $0 \cdot 91(0 \cdot 74-1 \cdot 11)$ & $0 \cdot 96(0 \cdot 89-1 \cdot 03)$ & $0.67(0.56-0.80)^{* * *}$ \\
\hline \multicolumn{4}{|l|}{ Distance to nearer of $\mathrm{BN} / \mathrm{BS}(\mathrm{km})$} \\
\hline$<2$ & Ref. & Ref. & Ref. \\
\hline $2-5$ & $1.67(0.94-2.99)$ & $0 \cdot 97(0 \cdot 83-1 \cdot 14)$ & $1 \cdot 41(1 \cdot 00-1 \cdot 99)^{*}$ \\
\hline$>5$ & $2 \cdot 78(1 \cdot 74-4 \cdot 43)^{* * *}$ & $0 \cdot 65(0 \cdot 57-0 \cdot 73)^{* * *}$ & $0 \cdot 74(0 \cdot 55-0 \cdot 98)^{*}$ \\
\hline \multicolumn{4}{|c|}{ Distance to nearest local $\mathrm{MCH}$ clinic $(\mathrm{km})$} \\
\hline$<2$ & Ref. & Ref. & Ref. \\
\hline $2-5$ & $0 \cdot 84(0 \cdot 66-1 \cdot 06)$ & $1 \cdot 24(1 \cdot 13-1 \cdot 35)^{* * *}$ & $1 \cdot 13(0 \cdot 94-1 \cdot 37)$ \\
\hline$>5$ & $0 \cdot 73(0 \cdot 36-1 \cdot 46)$ & $1.49(1 \cdot 21-1 \cdot 83)^{* * *}$ & $1 \cdot 21(0 \cdot 72-2 \cdot 03)$ \\
\hline \multicolumn{4}{|l|}{ Season } \\
\hline Dry & Ref. & Ref. & Ref. \\
\hline Rainy & $2 \cdot 46(2 \cdot 00-3 \cdot 02)^{* * *}$ & $2 \cdot 15(2 \cdot 01-2 \cdot 31)^{* * *}$ & $1 \cdot 21(1 \cdot 02-1 \cdot 44)^{*}$ \\
\hline \multicolumn{4}{|l|}{ Surveillance period } \\
\hline 1 Aug. 2000 to 31 Jan. 2002 & Ref. & Ref. & Ref. \\
\hline 1 Feb. 2002 to 31 Mar. 2003 & $0 \cdot 95(0 \cdot 72-1 \cdot 26)$ & $1 \cdot 02(0 \cdot 92-1 \cdot 12)$ & $1 \cdot 81(1 \cdot 34-2 \cdot 46)^{* * *}$ \\
\hline 1 Apr. 2003 to 30 Apr. 2004 & $0 \cdot 81(0 \cdot 58-1 \cdot 12)$ & $1.60(1.43-1 \cdot 78)^{* * *}$ & $3.33(2 \cdot 40-4.62)^{* * *}$ \\
\hline \multicolumn{4}{|c|}{ Age group during follow-up (months) } \\
\hline$<12$ & Ref. & Ref. & Ref. \\
\hline$\geqslant 12$ & $1 \cdot 02(0 \cdot 81-1 \cdot 30)$ & $0 \cdot 75(0 \cdot 69-0 \cdot 81)^{* * *}$ & $0.56(0 \cdot 46-0 \cdot 68)^{* * *}$ \\
\hline \multicolumn{4}{|l|}{ Gender } \\
\hline Male & Ref. & Ref. & Ref. \\
\hline Female & $1 \cdot 18(0 \cdot 96-1 \cdot 45)$ & $0 \cdot 90(0 \cdot 84-0 \cdot 96)^{* *}$ & $0 \cdot 85(0 \cdot 71-1 \cdot 00)^{*}$ \\
\hline \multicolumn{4}{|l|}{ Ethnic group } \\
\hline Mandinka & Ref. & Ref. & Ref. \\
\hline Fula & $1 \cdot 03(0 \cdot 79-1 \cdot 33)$ & $0 \cdot 82(0 \cdot 75-0 \cdot 90)^{* * *}$ & $0.93(0 \cdot 75-1 \cdot 16)$ \\
\hline Serahule & $0.70(0.53-0.94)^{* *}$ & $0.69(0.63-0.77)^{* * *}$ & $0 \cdot 91(0 \cdot 72-1 \cdot 15)$ \\
\hline Wollof & $0 \cdot 52(0 \cdot 29-0.96)^{*}$ & $1 \cdot 49(1 \cdot 28-1 \cdot 74)^{* * *}$ & $1 \cdot 51(1 \cdot 11-2 \cdot 05)^{* *}$ \\
\hline Other & $1 \cdot 26(0 \cdot 65-2 \cdot 46)$ & $0 \cdot 94(0 \cdot 71-1 \cdot 26)$ & $0 \cdot 68(0 \cdot 32-1 \cdot 46)$ \\
\hline
\end{tabular}

RR, Rate ratio; CI, confidence interval; Ref., reference group; BN, Bansang Hospital; BS, Basse Health Centre; MCH, Mother and Child Health.

$\dagger$ Adjusted rate ratios and 95\% confidence intervals from a piecewise exponential survival model that included all variables simultaneously.

$* P<0.05, * * P \leqslant 0.01, * * * P<0 \cdot 001$.

\section{DISCUSSION}

This study has shown that geographical access to healthcare facilities is an important determinant of care-seeking for pneumonia and of survival in children resident in a rural area of The Gambia.

Hypothesis 1 , namely that mortality rates increase with increasing distance from the nearest healthcare facility, has been supported by the data. Mortality was higher in children living further from BN/BS than in those living nearer to these facilities, i.e. the only facilities where blood transfusion, oxygen and injectable broad spectrum antibiotics were available round the clock. Reporting bias is very unlikely since each death was ascertained actively in the community through 3-monthly home visits, with follow-up of reported deaths by field supervisors, and/or at the paediatric wards of BN/BS.

The observed positive association of distance to the nearest $\mathrm{MCH}$ clinic with observed incidence of clinical pneumonia could possibly be related to unmeasured confounding factors as we did not collect information on socio-demographic or environmental circumstances of children. This finding was contrary to our 
hypothesis that those living further away from a healthcare facility would less likely to seek care and therefore to be detected (one component of hypothesis 2). Laboratory support for diagnosis of malaria was not present in $\mathrm{MCH}$ and outreach clinics. Early treatment of malaria could have resulted in an apparent reduction in the incidence of clinical pneumonia in children living nearer to outreach clinics as, without the support of laboratory diagnosis, these conditions are often confused [17]. There was no association between distance to $\mathrm{MCH}$ clinics and observed incidence of radiological pneumonia. This was expected as there was no X-ray facility at any of the MCH clinics.

The effect of distance to BN/BS on lower observed incidence of clinical and radiological pneumonia was supported by the data. It is not possible to determine whether this lower observed incidence was due to lower incidence of pneumonia per se or because of lower ascertainment of pneumonia cases due to poor access to and utilization of services at BN/BS. The most likely reason for this lower observed incidence of pneumonia was reduced case ascertainment, as the further away children lived the less likely they were to see trial clinical staff, who could only visit peripheral outreach clinics a maximum of once or twice each month even during the last year of the trial. These findings are supported by the results of a previous study in The Gambia by Weber et al. who observed that incidence rates of hospital admissions of children with ALRI and severe respiratory syncytial virus infection were highest in areas closest to the study hospitals [9].

The data from this study did not support hypothesis 3 , namely that distance from a healthcare facility influenced observed VE against radiological pneumonia. We had anticipated that children living close to a healthcare facility would receive treatment early in the course of their illness and be less likely to develop radiological pneumonia than those living further away, so that rates would be reduced in both controls and vaccinated children, reducing study power to detect VE. However, we found a lower observed incidence of radiological pneumonia in children living further away, which did not support our hypothesis. No association was found between increasing distance from healthcare facilities and observed VE against radiological pneumonia. The observed lower incidence of radiological pneumonia in children living further away from BN/BS suggests that a large proportion of children with advanced consolidation were not ascertained. This may have reduced our ability to detect an effect of distance on VE against radiological pneumonia.

The PVT did not record information on socioeconomic status of the parents of the trial participants. Therefore, we were unable to adjust the impact of distance on rates of pneumonia and mortality for differences in socioeconomic factors.

In our study we used straight-line distance as the measure of geographical access of a household to a healthcare facility. There are arguments that straightline distance is a suboptimal measure for studies of this kind since it ignores physical barriers such as rivers, swamps, hills and traffic systems. However, in our study area, south of the river, patients did not have to cross any such barriers. In a study in Yemen, straight-line distance and driving time were strongly linked with vaccine uptake [18]. We have also found a strong correlation between distance from BN/BS and mortality or radiological pneumonia regardless of whether the distance was measured as straight-line or estimated travel time (data not shown).

The findings of this study show a strong and significant effect of distance to major healthcare facilities on mortality and the observed incidence of pneumonia, findings that are likely to apply to other areas, where people live in similar conditions and the availability of adequate healthcare services is poor. Conjugate pneumococcal vaccines may be especially valuable in such areas. In addition, improving access of sick children to interventions such as blood transfusion, appropriate antimicrobial and oxygen therapy by improving means of transport could help in reducing the burden of pneumonia and overall child mortality in many parts of rural Africa.

\section{ACKNOWLEDGEMENTS}

We thank all staff of Basse Field Station, Medical Research Council Unit, The Gambia for their assistance and all the study children and their families for their participation. This analysis was supported by the Johns Hopkins University with funds provided by the Boards of the Global Alliance for Vaccines and Immunizations and the Vaccine Fund. The PVT was funded by grants from the National Institute of Allergy and Infectious Diseases at the USA National Institutes of Health through contract N01-AI-25477; WHO through contract V23/181/127; the Children's Vaccine Program at PATH; and US Agency for International Development. 


\section{DECLARATION OF INTEREST}

None.

\section{REFERENCES}

1. Becher $\mathbf{H}$, et al. Risk factors of infant and child mortality in rural Burkina Faso. Bulletin of the World Health Organization 2004; 82: 265-273.

2. Van den Broeck J, Eeckels R, Massa G. Maternal determinants of child survival in a rural African community. International Journal of Epidemiology 1996; 25: 9981004.

3. Schoeps A, et al. The effect of distance to health-care facilities on childhood mortality in rural Burkina Faso. American Journal of Epidemiology 2011; 173: 492-498.

4. Armstrong Schellenberg JR, et al. Health and survival of young children in southern Tanzania. BMC Public Health 2008; 8: 194.

5. Kadobera D, et al. The effect of distance to formal health facility on childhood mortality in rural Tanzania, 2005-2007. Global Health Action 2012; 5: $1-9$.

6. Kazembe LN, Kleinschmidt I, Sharp BL. Patterns of malaria-related hospital admissions and mortality among Malawian children: an example of spatial modelling of hospital register data. Malaria Journal 2006; 5: 93 .

7. Ewing VL, et al. Seasonal and geographic differences in treatment-seeking and household cost of febrile illness among children in Malawi. Malaria Journal 2011; 10: 32 .

8. Rahaman MM, et al. diarrhea clinic in rural Bangladesh: influence of distance, age, and sex on attendance and diarrheal mortality. American Journal of Public Health 1982; 72: 1124-1128.

9. Weber MW, et al. An epidemiological study of RSV infection in the Gambia. Bulletin of the World Health Organization 2002; 80: 562-568.
10. Blanford JI, et al. It's a long, long walk: accessibility to hospitals, maternity and integrated health centers in Niger. International Journal of Health Geographics 2012; 11: 24 .

11. Gove S. Integrated management of childhood illness by outpatient health workers: technical basis and overview. The WHO Working Group on Guidelines for Integrated Management of the Sick Child. Bulletin of the World Health Organization 1997; 75 Suppl 1; 7-24.

12. Cherian T, et al. Standardized interpretation of paediatric chest radiographs for the diagnosis of pneumonia in epidemiological studies. Bulletin of the World Health Organization 2005; 83: 353-359.

13. Cutts FT, et al. Efficacy of nine-valent pneumococcal conjugate vaccine against pneumonia and invasive pneumococcal disease in The Gambia: randomised, double-blind, placebo-controlled trial. Lancet 2005; 365: 1139-1146.

14. Hansen $\mathbf{J}$, et al. Effectiveness of heptavalent pneumococcal conjugate vaccine in children younger than 5 years of age for prevention of pneumonia: updated analysis using World Health Organization standardized interpretation of chest radiographs. Pediatric Infectious Disease Journal 2006; 25: 779-781.

15. Klugman KP, et al. A trial of a 9-valent pneumococcal conjugate vaccine in children with and those without HIV infection. New England Journal of Medicine 2003; 349: 1341-1348.

16. Tanser F. Methodology for optimising location of new primary health care facilities in rural communities: a case study in KwaZulu-Natal, South Africa. Journal of Epidemiology and Community Health 2006; 60: 846850.

17. O'Dempsey TJ, et al. Overlap in the clinical features of pneumonia and malaria in African children. Transactions of the Royal Society of Tropical Medicine and Hygiene 1993; 87: 662-665.

18. Al-Taiar A, et al. Physical accessibility and utilization of health services in Yemen. International Journal of Health Geographics 2010; 9: 38. 